\title{
DIGITAL ETHNOGRAPHERS ON THE MOVE - AN UNEXPECTED PROPOSAL
}

\author{
Johanna Sumiala and Minttu Tikka*
}

\begin{abstract}
This article explores what digital media ethnography as a methodological approach can offer to the study of contiguous media events with an unexpected, violent and fluid nature. Emphasising the role of media events in the present organisation of social life, we as digital media anthropologists acknowledge the tendency in the current digital media environment to eventise and spectacularise social life. This development serves the power-related purposes of attention seeking and public recognition in the digital world. The article is structured as follows: first, we provide a brief outline of the field of digital media ethnography in relation to the study of media event; second, we identify what we claim are three key methodological dilemmas in applying digital media ethnography to the study of today's digitally circulating media events (scale, mobility and agency) and reflect on them in the context of our methodological positioning; third, we conclude this article by considering some epistemological and ontological implications of this methodological endeavour in relation to what can be called the 'meta-field' and the related instability in current digital research.
\end{abstract}

Keywords: digital media ethnography; scale; mobility; agency; meta-field; media event; unexpectedness 


\section{INTRODUCTION-DIGITAL RESEARCH ON THE MOVE}

Late on the evening of Tuesday, 11 December 2018, one of our co-authors, Johanna, received a WhatsApp message while attending a faculty seasonal party in Helsinki. The message came from a colleague, and informed her and the rest of the research team about a shooting in Strasbourg. In this attack, a gunman who had a terrorist motive opened fire near a crowded Christmas market in the French city of Strasbourg, killing five people. After a massive manhunt, the police shot the perpetrator dead. Johanna received the message through the WhatsApp Hybrid Terrorizing chat group created for immediate communication about acute research matters. The next morning, when the research team members switched on their computers, the Strasbourg shooting continued to be breaking news on several international media outlets, and hashtags such as \#strasbourg, \#strasbourgattack and \#strasbourgattaque were circulated prominently on Twitter and remediated elsewhere on digital media. Affected by the tragedy, and also reflecting on the intense character of the initial social media response, the team decided to systematically collect data on this disruptive media event. While the event kept unfolding on diverse digital media, the team had to direct its focus to making decisions concerning the data collection: which hashtags to scope, which media to scrape, who would do so and on which platforms to conduct qualitative digital ethnography. By Wednesday evening, the team had utilised computational and ethnographic tools to gather and store news articles, tweets, Instagram posts and YouTube data.

This example of the first twenty-four hours of data gathering in our research project illustrates the high pace and fluid process by which digital media ethnographic projects may take off in today's hybrid media environment (Chadwick 2013; Sumiala et al. 2016). Most importantly, in this article, we wish to methodologically highlight what the 'liveness' and related unexpectedness of these events demands in research design and what it means to try to 'catch up' with digital media on the move. We may well call this empirical exercise a 'live experiment', following Celia Lury and Nina Wakeford's (2014, p. 1-24) insight into the methodological thinking in present digital life worlds. In the following, we identify three key methodological dilemmas (relating to scale, mobility and agency), and reflect on them in the context of 'liveness' of digital media ethnography.

By no means do we claim to be the only researchers working on concerns such as these. Lury and Wakeford (2014), Paul Rabinow and Anthony Stavrianakis (2014), Christine Hine (2015), Noortje Marres (2017) and many others have made significant contributions to this methodological endeavour to critically reflect on how to do research on 'what is happening in the present digital world' and to better grasp the present digital world's ongoingness, relationality, contingency and sensuousness in all its varieties and shapes (Lury and Wakeford 2014, p. 2).

In our methodological effort, we wish to reflect, in particular, on what digital media ethnography as a methodological approach can offer to the study of such 
contiguous events with an unexpected and fluid nature. Our approach to this enterprise draws on our continuing research on events in digital media worlds and ethnographic investigation of them (see e.g. Sumiala et al. 2016; Sumiala et al. 2018; Valaskivi et al. 2019).

In the following, we first provide some key definitions, and a brief outline of the field of digital media ethnography in relation to the study of media events, and we contextualise our approach within the research field and approach of media anthropology and digital ethnography. Second, we identify what we claim are three key methodological dilemmas in applying digital media ethnography to the study of today's digitally circulating media events (scale, mobility and agency) and reflect on them in the context of our methodological positioning. Third, we conclude this article by considering some epistemological and ontological implications of this methodological endeavour in relation to what can be called the 'meta-field' (e.g. Caliandro 2018) and the related instability in current digital research.

\section{MEDIA ANTHROPOLOGY GOES DIGITAL}

To begin this exercise, we need some preliminary definitions to position ourselves. As a research approach, digital media ethnography draws inspiration from various intellectual sources and traditions, particularly media anthropology and digital ethnography. Media anthropology is often described as an anthropology of contemporary societies (see e.g. Coman 2005). It is interested in the multitude of ways in which people connect to (or disconnect from) their social worlds through media technologies (see e.g. Ginsburg, Abu-Lughod and Larkin 2002). In addition, media anthropology explores how the interplay between people and technologies shapes their social experiences and the ways in which individual and collective lives become mediated, or mediatized, in both 'old' media and 'new' media settings and contexts (see e.g. Spitulnik 1993; Coman and Rothenbuhler 2005; Askew 2008). Media anthropologists, in line with their anthropological heritage, thus encourage scholars' conceptual engagement with not only the material and rational aspects of human life but also the affective and symbolic construction of mediated reality (see e.g. Coman and Rothenbuhler 2005, p. 1).

Accordingly, media anthropologists have turned their interest to the study of media events (Dayan and Katz 1992) and their social and cultural implications for contemporary individual and collective lives (Pink et al. 2016). Emphasising the role of media events in the present organisation of social life, media anthropologists (Sumiala and Räisä 2020) acknowledge the tendency in the current digital media environment to eventise and spectacularise social life, which serves the powerrelated purposes of attention seeking and public recognition in the digital world (cf. Rojek 2013; Wagner-Pacifici 2017). Media anthropologists are also interested in the diverse ways in which media events are mediated and engaged by multiple publics in a range of local and glocal settings (Pink et al. 2016, p. 147-165). For 
that purpose, media anthropologists have developed a processual view of media events that approaches events not simply as distinct ritual affirmations but also as relational processes in which series of things come together and create new relationships between events and their mediated perceptions (Pink et al. 2016, p. 147-165). Consequently, media anthropologists argue that digital ethnography provides useful tools to give nuanced processual attention to such dynamics in today's media events, along with the means to investigate them in a variety of digitally saturated contexts.

\section{3 'REAL' AND/OR 'VIRTUAL' IN DIGITAL ETHNOGRAPHY}

A main issue in applying digital media ethnography to the study of today's media events concerns the following question: how to think about and describe the relationship between 'real' and digital, online and virtual environments in ethnographic fieldwork. This question takes the reader to the very core of the work of (digital) ethnography (see e.g. Hine 2015; Pink et al., 2016; Postill and Pink 2012; Rogers 2009). In the 1990s, sometimes called the Web 1.0 era, digital ethnographic research primarily focused on online communities perceived as separate from the 'real world' (Rheingold 1994). The conceptualisations of these virtual communities commonly held at that time are said to have resembled the early-twentieth-century anthropological ideas of far-away fields (Dicks et al. 2005, p. 116-117).

As is well recognised, in recent decades, the digital environment has transformed in many ways, and the digital, in its different forms, has become an essential, inseparable component of everyday life, including the experience of and participation in today's media events (cf. Postill and Pink 2012). This digitalisation of everyday life, if you will, has implications for ethnographic studies. According to Sarah Pink (2016):

...ethnographers have long since worked with media, both as a research method, as a research topic, and perhaps most importantly as something that we acknowledge is an almost inevitable and universal element of everyday life. As digital technologies are increasingly ubiquitous in everyday life, as well as in the more extraordinary events and activities in which people become involved, then it becomes important to do research in a way that accounts for this' (Pink 2016, p. 161).

Expressing an even more explicit position on the incorporation of the digital into ethnographic practice, Ronald Hallett and Kristen Barber $(2014,307)$ argued that 'it is no longer imaginable to conduct ethnography without considering online spaces'.

These methodological advancements have shifted the ethnographic focus from isolated, virtual communities to transient, fluid, ephemeral fields of social media (Airoldi 2018; Caliandro 2018). Simultaneously, ethnography has faced new 
theoretical and methodological challenges. According to Alessandro Caliandro $(2018,557)$, 'the fact that social media tend to structure online interactions across very fluid, ephemeral and dispersed social forms' presents novel challenges to classical anthropological and ethnographic categories such as field, community, identity and ethics. Caliandro (2018, p. 557) argued that:

...on the methodological level, social media configure themselves as environments that provide the ethnographer with an array of present tools that actually organise the space and flow of interaction (think about Twitter's retweets and hashtags) (Marres and Gerlitz 2015), which in some ways channel and constrain the scope of action of the ethnographer and challenge the approach itself.

Against this background, what seems to be both methodologically challenging and promising for contemporary ethnography is not adapting classical analysis qualitative techniques to online environments but, instead, understanding what we can learn from online environments about new methods and languages useful to reinnovate the discipline of ethnography (Ruppert, Law and Savage 2013; Pink et al. 2016). Digital media ethnography, as we argue in this article, constitutes one such attempt.

Today's digital media ethnography thus has a methodological scope that gives serious consideration to the contemporary mobile condition of social media (Hine 2015; Kozinets 2016; Airoldi 2018; Caliandro 2018). From the perspective of digital media ethnography and the study of media events, this new empirical thinking must include three interconnected dimensions. First, in digital media ethnography, the line between 'the real' and 'the virtual' should be thought of as a continuum rather than two separate realms of reality. This follows naturally from the rich literature in digital culture and internet scholarship that has long discussed and problematised such distinctions (see e.g. Boellstorff et al. 2012; Hine 2015). It follows from this that empirical researchers need to be able to move from one realm to the other and think them as two profoundly intertwined realms of people's reality. Second, in digital media ethnography, 'the real' and 'the virtual' have a relationship of mutual dependence. Media events cannot be created ex nibilo; instead, they take place in certain physical locations (in the aforementioned case, the shooting in the Christmas market) from where they instantaneously spread to digital media and communication networks in the form of information and messages exchanged by actors. In this context, various actors including journalists, authorities, ordinary media users and, in some cases, perpetrators participate in the communicative construction of events on and outside the digital media. This communication is dispersed across both social media and online news media, creating a unique empirical context for the ethnographic study of such events (Chadwick 2013; Sumiala et al. 2018; Sumiala and Räisä 2020). Third, digital media ethnography can be understood as a method to study 'natively digital' data. 
Richard Rogers (2019, p. 6) distinguished between digitised and natively digital data and methods. The former refers to 'old' methods that have migrated to digital environment; virtual ethnography is a case in point here. The latter refers to digital methods designed to use born-digital data, hence 'native' in the name (Rogers 2019, p. 4). ${ }^{1}$

Moreover, digital media ethnography allows scholars to follow connections through a variety of digital media landscapes instead of being fixed to certain platforms (whether social media or professional news media). Digital media ethnographers can consider multifaceted views, travel among different sites, platforms and channels (including, when necessary, the complex interplay between online and offline communication) and explore how things are made meaningful and are experienced in varied digital contexts (see e.g. Hine 2015). Through this flexible, reflexive research practice, we argue, it is possible to begin to gain new understandings of the workings of today's media events and how people connect to them at various levels for diverse purposes.

\section{THREE DILEMMAS TO GRASP IN DIGITAL MEDIA ETHNOGRAPHY}

Based on our real-time ethnographic exercise on the Strasbourg shooting, we argue that studying contemporary media events and the related eventisation of social life of individuals and collectives in today's digital environment raises three key dilemmas demanding further investigation: the scale of digital media ethnographic research, the mobility of the digital field and the relationships between human and non-human actors when following such events in real time. In the following sections, we address these three dilemmas in more theoretical detail and combine our discussion with empirical issues triggered by our fieldwork on the Strasbourg shooting.

\subsection{Scale}

The first dilemma to be tackled in digital media ethnography of violent and disruptive media events has to do with scale. This dilemma is triggered by the fact that the scale of the data that emerges as a response to violent media events is well beyond the human perception. It is widely acknowledged fact that digital media, combining both news media and social media, has the power to expand time-space communication among people in different locations and contexts during events (see e.g. Kraemer 2017; Sumiala 2013). Digital media thus extends the scale of communication beyond the micro and macro spheres of social reality (see also Couldry 2012). By doing so, it also unwraps the place-society isomorphism in

\footnotetext{
${ }^{1}$ See the introduction to this special issue for an extensive literature review of digital ethnography and related methodologies.
} 
which people are thought to construct meanings and to create and maintain social worlds during media events (cf. Inda and Rosaldo 2002). These conditions shaped the experience of fieldwork on the Strasbourg Christmas market shooting in many ways. Our research team was able to follow the media event unfolding on our screens while we were physically thousands of kilometres away from the crime scene in Strasbourg, France. Moreover, we were geographically spread throughout towns and cities in Finland, yet through digital media, we were able to communicate in real time to exchange field notes and share observations on the field and the data gathered.

In theoretical terms, we can identify at least two ways of thinking about the implications of scale in the empirical study of digital media ethnography of media events. The first and perhaps the most conventional way of thinking about scale relates to its globalised scope. Jonathan Xavier Inda and Renato Rosaldo (2002, p. 9) described globalisation as the increased interconnections of people, goods and ideas shaped by compressed spatial and temporal horizons. This compression of space and time in communication enables media events to make action possible from a distance. In this frame of thinking, digital media communication may be carried out simultaneously on local, national and global levels. Simultaneous digital presences on various scales pose major challenges in digital media ethnographic research collecting data on events as these presences unravel any fixed ideas about the ways in which data and place are connected in this empirical reality. It follows that in the flow of media events, the local typically is embedded in the global, and vice versa.

When the shooting in Strasbourg took place, news, hashtags, videos, posts and memes provoked by it began to circulate on diverse digital media platforms including both online news media and social media, particularly Twitter, YouTube and Instagram. Hence, to try to better grasp the scale of this incident, we had to look beyond local and national contexts for our ethnographic observations. In other words, it was not enough for us to focus on one platform, one discussion forum, one online community or one national media such as Le Monde or even 'French Twitter'. To match the scale of this violent event, we had to expand the scale of our data gathering and simultaneously collect data from various digital platforms and across diverse platform. Nevertheless, we came nowhere close to gathering the 'complete data'; instead, we grasped fragments of diverse, rather heterogeneous data sets. In other words, the scale of the event is so vast that it can never be fully empirically grasped. Yet, we argue that this approach of immediate fieldwork simultaneously expanded into variety of digital platforms, although not complete, allowed us to follow multiple digital field sites and collect both computational and ethnographic data on the event as it unfolded in multiple locations simultaneously. This decision made it possible for us begin to tackle the scale of the Strasbourg Christmas market shooting as a disruptive media event of global measure (cf. Couldry, Hepp and Krotz 2010). 
Another way of thinking about scale in the study of digital media ethnography of media events is what we may call 'flat ontology' (cf. Couldry 2012, p. 27). Following Bruno Latour's $(1999,2005)$ Actor Network Theory, we may claim that there is no 'natural' scale in digital media. 'Largeness' and 'smallness' are merely extensions of the same social reality. For Latour (1999), scale, therefore, is best characterised as flat and folded (see also Couldry 2012, p. 27).

In the case of the Strasbourg Christmas market shooting, the idea of flat ontology referred to an interpretive framework in which the social lives surrounding the event took place 'here' and 'now' in the digital encounters with no outside references beyond digital media. This approach has certain limitations as it does not recognise the relationships of events to the contexts in which people's digital actions take place. Here, for example, we can think about the eyewitnesses to the attack in the Christmas market who posted about it on social media such as Twitter. We may well assume that these people did not witness the attacks in the vacuum, but interpreted them in a framework of broader histories related to such terrorist attacks - the Berlin Christmas market attack in 2016 being one possible point of reference (see e.g. Sumiala and Räisä 2020). The idea of flat ontology nevertheless provides certain useful ways of thinking about scale as one horizon along which digital activities are performed. For digital media ethnographers collecting data on media events from digital media, this flatness of scale also opens up new ways of thinking about the construction of the social in such occasions- not so much as a place but as an encounter-specific activity. We argue that the issue of flatness also encourages digital media ethnographers to apply new technological tools to conduct ethnographic research that incorporates computational methods to explore new scale social encounters in such violent media event (see also Sumiala et al. 2016).

Aligning with Hine's (2015, p. 4) insights, ethnographers always have limited ability to encompass the whole situation. In other words, ethnography is conducted on a scale determined by human perceptual capacity. To mitigate this limited capacity to do research, digital media ethnographers prefer the collective ethnography approach as a methodological strategy. Following this line of thinking, our research team studied the same event but from different perspectives by combining computational data collection methods with ethnography (see also Caliandro 2018). During the data collection, one team member started to collect Twitter data through a streaming Application Programming Interface (API) that allowed adding search terms. We also employed other 'methods of the medium' (Rogers 2019) to grasp the ongoing and constantly updating situation, such as manually scraping YouTube, screen-recording Instagram and taking screenshots of Twitter and news media sites.

\subsection{Mobility}

The second dilemma in digital media ethnography of today's disruptive media events involves the empirical handling of ongoing flows of data, people and ideas 
during data gathering. John Urry (2007, p. 6, 9) famously called this shift in research the 'mobility turn' to a research focus on the movement, mobility and contingent ordering of social life in a variety of social and cultural contexts. In digital media ethnography of media events, this turn entails paying special attention to the multiple ways in which data, people and ideas move and travel across digital contexts and the kinds of flows their movement creates (Urry 2007, p. 6). Research methods, in short, need to be put 'on the move' as they must be able to efficiently follow their research objects (Urry 2007, p. 41). Urry (2007, p. 40) introduced three methods applicable in digital media ethnography. The first method consists of 'directly observing mobile bodies or observing them in digitally enhanced forms' (Urry 2007, p. 40). In the second approach, the researcher, in a kind of 'co-present immersion' (Urry 2007, p. 40), moves with 'modes of movement' and employs a range of observations and digital data gathering in this process of 'travelling with' the research objects. Third, Urry (2007, p. 40) suggested an approach in which the objects of study are asked to keep 'time-space' diaries and make notes about what they do, where they do these things, how they move during these periods and what modes of movement they use in these situations. These diaries can be textual, pictorial, digital or, in many cases, combinations of these three.

Urry's (2007) proposal of the mobile turn resonates with the older idea of multi-sited ethnography introduced by George Marcus (1995) and later elaborated by many digital ethnography scholars such as Jennie Germann Molz (2006), Christine Hine (2015), Massimo Airoldi (2018) and Alessandro Caliandro (2018). The main proposition of Marcus' (1995, p. 96) multi-sited ethnography is that ethnographic research should move 'out from the single sites and local situations of ethnographic research design to examine the circulation of cultural meanings, objects, and identities in diffuse time-space'. Within digital media ethnography, digital world(s) provide such multi-sited field(s), and in recent years, the idea of multi-sitedness has been applied and elaborated in various social media contexts (see e.g. Airoldi 2018; Caliandro 2018). Another crucial aspect of Marcus' (1995, p. 96) thinking that is highly relevant to digital media ethnography is the methodological rule to 'follow the thing'. This imperative 'to follow' encourages digital media ethnographers to trace different types of actors and messages across a variety of online platforms.

Such following is rarely linear (Sumiala et al. 2018) but instead consists of circulating moves among multiple actors, platforms and messages (see also Latour 1999). To give one example, one team member followed the Strasbourg Christmas market shooting event on Twitter. This task included following streams of messages based on emerging hashtags such as \#StrasbourgShooting and \#JesuisStrasbourg. However, these messages contained links and referred to different actors that led to other platforms. 'To follow the thing', therefore, requires following diverse representations and actors, often across multiple digital sites, which may easily blur the boundaries between the event and other flows of 
messages. Those conducting fieldwork thus may get lost in multi-sitedness of the digital field. To avoid this trap, it is important to reflect on the process of following the event and to collectively discuss potential digital paths and their relevance to it. This is a lesson we learnt while conducting fieldwork on the Strasbourg shooting. Sometimes, a link that looks a side-track may lead to an important finding in the field. It, therefore, is important to keep the digital fieldwork process organic and open to immediate reflections.

The last aspect of mobility raised in this context relates to the question of how to keep up with the cyclical movement in these digital platforms and their related research subjects. This concern is closely connected to the 'liveness' (see e.g. Zelizer 2018) of today's media events. Indeed, 'the live' circulation of data, people and ideas creates media events in the present digital age. This very liveness of events and the related, intensified speed of circulation have been increasingly discussed within the framework of the concept of acceleration (see e.g. Hassan 2009; Rosa 2015). In this context, the idea of acceleration points to the temporal and spatial speeding up of events and draws scholarly attention to the speed and the consequent instability of movement in digital media ethnographic analysis of such events. The logic of acceleration forces the participants in current media events to post and share messages and make sense of these events at ever faster paces (e.g. Sumiala et al. 2018 , p. 21). This greater speed of communication poses major challenges for digital media ethnographers' attempts to keep up with the rapidity and instability of floating transmedial communication. Acceleration also has ethical implications for digital media ethnographers. Research has demonstrated that the acceleration of communication in today's media events tends to facilitate stereotypical, untruthful and prejudiced communication, polarising the event participants and other affected parties in society (see e.g. Zelizer 2018).

When conducting fieldwork on the Strasbourg Christmas market shooting, we had to take into account that not only people but also messages such as tweets, memes and videos were circulating and in constant flux. Consequently, new information was uploaded on online news media all the time as new facts about the event were established, and new ideas were associated with it. One such affective dimension that vividly circulated after the Strasbourg shooting was public mourning performed on and via digital media. In this process typically involving sharing messages of solidarity and sympathy for victims, certain symbols such as white storks - a symbol of Strasbourg-began to circulate on digital media in different forms, styles and shapes.

Moreover, old information disappeared and was reshaped and remediated. During the process of immediate fieldwork, it often is difficult to identify the truth value of the information on the event circulating on digital media. In the Strasbourg shooting, as in other violent events, immediate uncertainty surrounded the cause of the attack and the identities of the perpetrator and the victims. The digital media ethnographer's ethical problem is to decide whose fate to follow in a disruptive media event in which battle over media attention, visibility and recognition is a 
typical feature (Sumiala et al., 2018). To give an example, perpetrators may well have left digital traces such as manifests or live recordings of their violence (Sumiala et al., 2018). In such as case, one has to decide whether to focus on the public representations of the perpetrator and their self-scripted narratives or to turn more attention to the victims' suffering and the solidarity offered to them in and via digital media. In real-life ethnographic encounters, this issue rarely is either/or but, instead, is both/and. However, when writing ethnographies on the disruptive media event, one cannot escape the question of to whom and what the research gives visibility in the present condition characterised by constant attention seeking.

\subsection{Agency}

The third dilemma in digital media ethnographic study of violent media events deals with the issue of agency. One needs to ask, who qualifies as an actor in today's disruptive media events (cf. Marres 2017, p. 185). And what is more, can we think of technologies as actors possessing agency in such events? When discussing mobility as a dilemma in the digital media ethnographic study of violent media events, we briefly mentioned that the imperative to follow targets both human and non-human actors. Here, we wish to explore this idea in more detail. In the digital media ethnographic study of media events, this idea of human-non-human interactions typically is associated with Latour's $(1999 ; 2005)$ attempt to unravel the dichotomy between people and things. This frame of thinking invites digital media ethnographers to examine the various ways in which people and objects (e.g. news, tweets, memes, posts and videos) are assembled and reassembled through time-space in the multiple digital environments of today's media events (cf. Urry 2007, p. 50). This multitude of connections resonates with John Law's (1994) ideas posed in the 1990s, arguing that humans are intricately networked with technology. Here, we may think of the software, databases and algorithms that shape the ways in which the digital social worlds of media events are created and shaped today.

The social reality of today's media events thus is brought to the fore through complex processes of human actions embedded within computational logics and algorithmic constellations. Simply put, the more (human) actors click and share certain types of materials related to events, the more these actors are offered those contents on their screens and in their news feeds. Jose van Dijck (2013) called this quantified sociality. Consequently, digital media ethnographers must adopt a methodological orientation that enables them to empirically trace these human and technological associations and encounters in a variety of networks created in and around today's media events. During the 'mass media' era, actors also played a central role in creating media events (Dayan and Katz 1992), but we argue that rigorous digital media ethnographic analysis of today's media events requires conceptually broadening the category of actors to include non-human actors and agency in events. Furthermore, it is necessary to pay close attention to the 
intensified, globalised dynamics among the actors contributing to events (see e.g. Sumiala et al. 2018, p. 17-18).

In the case of the Strasbourg shooting, we identified three different groups of actors that all played important roles in constructing the event: representations, platforms and humans (whom we encountered through representations). In our digital media ethnography, representations were given a central role in the fieldwork. We followed tweets, news stories, YouTube videos, memes and Instagram posts - all media representations. Memes were one example of the social lives of representations identified in the fieldwork. Soon after the attack took place, two visual representations started to circulate on social media platforms such as Twitter and Instagram: imagery related to Strasbourg Cathedral and storks, which both had symbolic relevance to Strasbourg. These visual representations appeared in different forms as both drawings and photographs and were used to express collective mourning and solidarity with the victims.

As discussed, digital platforms such as Twitter and Instagram were actively used in the case of the Strasbourg shooting, as in many other terror attacks, to disseminate information and express collective emotions (Eriksson Krutrök and Lindgren 2018). We argue that as techno-social constellations, these platforms also shaped the event by giving more visibility to certain representations than others. Moreover, based on our previous research on the Charlie Hebdo attacks, we knew that digital platforms are harnessed to spread violent imageries (Sumiala et al. 2018). It, therefore, was important to acknowledge the agency of the platforms in the course of fieldwork and reflect how this platform agency may shape the flows of messages and related interpretations of the event.

Lastly, in the case of the Strasbourg shooting, we could identify that the human actors who appeared in our fieldwork were journalists, police and ordinary people, and all these actors were identified in our digital media material. For example, YouTube was soon filled with news videos from media agencies in which journalists on the scene reported about the unfolding events while police officers in bulletproof vests and helmets conducted security operations. Moreover, ordinary people posted videos and messages about their experiences of the event on social media. Many of these people were visiting Strasbourg when the attack took place. It thus appears that we were dealing with a complex mixture of actors and related potentials to shape and influence not only our fieldwork but the social reality created around the Strasbourg shooting as a media event.

Digital media ethnography thus challenges conventional anthropocentric thinking about how the social worlds of media events are created and maintained in their current condition and who puts these social encounters into action. Digital media ethnography also pushes scholars to re-think the centrality of human agency in managing these processes and to contest fixed anthropological attempts to interpret such events and the related interactions and encounters (cf. Tsing 2002). 


\section{CONCLUDING REMARKS-DEALING WITH 'UNEXPECTEDNESS' IN DIGITAL MEDIA ETHNOGRAPHY}

In this article, we have examined digital media ethnography as a possible methodological means to more fully grasp the empirical complexity of the digital research environment as a research site, particularly within the study of violent media events of disruptive and global nature. We acknowledge our limitations to offer any inclusive solutions for digital research scholars. Many issues still require further intellectual inputs and efforts. For instance, more work needs to be carried out to better combine computational methods of data science with an ethnographic orientation. Making this work successful demands addressing the idea of the metafield (Airoldi 2018). As when using other digital research methods to focus on digital media worlds, digital media ethnographers have to develop a certain dual understanding of the idea of the field as a research site. The digital field is a research site that not only is deeply multi-sited, as described in this article, but also consists of different layers. According to Airoldi (2018, p. 666), the meta-field comes to exist due to the very act of following a key word or an algorithm as a practice of ethnographic fieldwork. Airoldi (2018, p. 665) distinguished 'liquid' meta-fields from 'solid' digital sites but argued that they have overlapping natures. To be able to navigate these complex meta-fields always present in digital media research, digital media ethnographers need to better understand the underlining algorithmic logics of these digital media sites (which often demands more intense collaboration with data scientists) and the cultural and social logics embedded in these encounters.

In our experience of fieldwork on the Strasbourg Christmas market shooting, we, as digital media ethnographers, had to cultivate a highly complex epistemology to enable coping with the issues of meta-field, scale, mobility and agency in such research simultaneously. We, as ethnographers, could grasp the immediate social life of the representations of the event dispersed throughout diverse platforms such as online news media, Twitter and YouTube. Although partial, our fieldwork yielded empirical evidence of a phenomenon that consisted of global elements, was constantly moving and involved a rich variety of actors. However, our ethnography did not make visible how the logic(s) of algorithms shaped what we were able to follow on digital media. To help fill this gap, we applied computational methods. For example, our colleague, a data scientist, was able to build an API that helped us gather data from Twitter. However, it needs to be acknowledged that the data are available only as long as Twitter and other social media corporations allow such mining. How open or closed these interfaces are depends on number factors, including business models, profit purposes and many factors beyond the influence of data scientists. 
Achieving this end connected with the issues of meta field, scale, mobility and agency requires questioning certain pre-digital ideas of research. Instead of aiming to achieve all-embracing, transparent, stable data collection of today's media events, digital media ethnography, as a methodological approach, must acknowledge the partial, incomplete nature of present digital data as always 'broken' (Pink et al. 2018) and unfinished, no matter how much data scientists' tools used to complement ethnographic data gathering. By so doing, digital media ethnographers can attempt to adapt to the epistemological and ontological conditions of the present digital age shaped by ongoingness, relationality, contingency (Lury and Wakeford 2014) and-we would like to addunexpectedness, which so profoundly characterises digital research in our time.

Finally, the Strasbourg Christmas market shooting in December 2018 did not become a large-scale, global media event. However, it was a human tragedy powerful enough to stir contemporary digital lives and push communication on the move. At the moment of deciding whether to follow this event and what data to gather, the outcomes could not be known. Digital media ethnographers working on such 'live experiments' (Lury and Wakeford 2014) must make decisions in real time in real-world situations that cannot be predetermined, let alone measured or controlled. This very condition of unexpectedness, in our view, poses the major challenge for digital media ethnography and practitioners today. The uncertainty of communication in digital social worlds during violent media events contests all static positions imagined for ethnographers to take. Hence, today's digital media ethnographers have to tackle with new dilemmas triggered by the amount and quantity of material circulating on the event (scale), multi-directional movement and accelerated circulation of data (mobility) as well as expansion of the category of actors involved in shaping the event including both human and non-human actors. To confront these dilemmas a media ethnographer has to be willing to problematise any canonised, fixed, pre-digital ideas about the nature of the knowledge achieved by conducting ethnography, relationship between an ethnographer and their field and the material gathered during fieldwork. This type of orientation, we argue, demands willingness to search for new forms of collaboration with data scientists and readiness to bring ethnography as a methodological approach into a more profound dialogue with computational means of doing research in digital contexts. Even more so, it requires ability to tolerate abruptness of one's field work and brokenness of the data gathered in such ephemeral conditions. Beginning to realise how massive this challenge is marks the first and the most crucial step as we seek to understand how profoundly not only our ethnographic research but also we, as ethnographers and our ideas about research, are put on the move in the present digital age. 


\section{FUNDING STATEMENT AND ACKNOWLEDGMENTS}

The authors disclosed receipt of the following financial support for the research, authorship, and/ or publication of this article: This research has been funded by the Academy of Finland. Hybrid Terrorizing (HYTE) Developing a new model for the study of global media events of terrorist violence. Decision No. 308854

\section{REFERENCES}

Airoldi, M. (2018) 'Ethnography and the digital fields of social media', International Journal of Social Research Methodology, 21(6), 661-673.

Askew, K. (2008) 'Introduction', in Askew, K. and Wilk, R. R. (eds) The Anthropology of Media. A Reader. Malden, MA: Blackwell Publishing, pp. 113.

Boellstorff, T., Nardi, B., Pearce, C., \& Taylor, T. L. (2012). Ethnography and Virtual

Worlds. Princeton, NJ: Princeton University Press.

Caliandro, A. (2018) 'Digital methods for ethnography: Analytical concepts for ethnographers exploring social media environments', Journal of Contemporary Ethnography, 47(5), 551-578.

Chadwick, A. (2013) The Hybrid Media System: Politics and Power. Oxford: Oxford University Press.

Coman, M. (2005) 'The Profanity of Media', in Rothenbuhler, E. W. and Coman, M. (eds) Media Anthropology. Thousand Oaks: Sage, pp. 26-35.

Coman, M. and Rothenbuhler, E. (2005) 'The Promise of Media Anthropology', in Rothenbuhler, E. W. and Coman, M (eds) Media Antbropology.

Thousand Oaks: Sage, pp. 1-25.

Couldry, N. (2012) Media, Society, World: Social Theory and Digital Media Practice. Cambridge: Polity Press.

Couldry, N., Hepp, A. and Krotz, F. (eds.) (2010) Media Events in a Global Age. London: Routledge.

Dayan, D. and Katz, E. (1992) Media Events: The Live Broadcasting of History. Cambridge: Harvard University Press.

Dicks, B., Mason, B., Coffey, A. and Atkinson, P. (2005) Qualitative Research and Hypermedia: Ethnography for the Digital Age. London: Sage.

Eriksson Krutrök, M. and Lindgren, S. (2018) 'Continued contexts of terror: analyzing temporal patterns of hashtag co-occurrence as discursive articulations', Social Media + Society, 4(4), 1-11.

Ginsburg, F. D., Abu-Lughod, L. and Larkin, B. (eds) (2002) Media Worlds. Anthropology on New Terrain. Berkeley: University of California Press.

Hallett, R. E. and Barber, K. (2014) 'Ethnographic research in a cyber era', Journal of Contemporary Ethnography, 43(3), 306-330. 
Hassan, R. (2009) Empires of Speed: Time and the Acceleration of Politics and Society. Leiden: Brill.

Hine, C. (2015) Ethnography for the Internet: Embedded, Embodied, and Everyday. London: Bloomsbury.

Inda, J. X. and Rosaldo, R. (2002) 'Introduction: A World in Motion', in Inda, J. X. and Rosaldo, R. (eds), The Anthropology of Globalization. A Reader. Malden, MA: Blackwell Publishing, pp. 1-36.

Kozinets, R. V. (2016) Netnography, $2^{\text {nd }}$ edition. London: Sage.

Kraemer, J. (2017) 'Locating Emerging Media: Ethnographic Reflections on Culture, Selfhood, and Place', in Hjorth, L., Horst, H., Galloway, A. and Bell, G. (eds) The Routledge Companion to Digital Ethnography. New York: Routledge, pp. 180-199.

Latour, B. (1999) 'On recalling ANT', in Law, J. and Hassard, J. (eds) Actor Network Theory and After. Malden, MA: Blackwell, pp. 15-25.

Latour, B. (2005) Reassembling the Social. An Introduction to Actor-Network-Theory. Oxford: Oxford University Press.

Law, J. (1994) Organizing Modernity. Oxford: Basil Blackwell.

Lury, C. and Wakeford, N. (2014) 'Introduction: A Perpetual Inventory', in Lury, C. and Wakeford, N. (eds) Inventive Methods: The Happening of the Social. Abingdon: Routledge, pp. 1-24.

Marcus, G. E. (1995). 'Ethnography in/of the world system: the emergence of multi-sited ethnography', Annual Review of Anthropology, 24, 95-117.

Marres, N. (2017) Digital Sociology. The Reinvention of Social Research. Cambridge: Polity Press.

Marres, N. and Gerlitz, C. (2015) 'Interface methods: renegotiating relations between digital social research, STS and sociology', Sociological Review, 64(1), 21-46.

Molz, J. G. (2006) 'Watch us wander: mobile surveillance and the surveillance of mobility', Environment and Planning A, 38(2), 377-393.

Pink, S. (2016) 'Experience: Digital Ethnography', in Kubitschko, S. and Kaun, A. (eds) Innovative Methods in Media and Communication Research. Cham: Palgrave MacMillan, 161-166.

Pink, S., Horst, H., Postill, J., Hjorth, L., Lewis, T. and Tacchi, J. (2016) Digital Ethnography: Principles and Practices. London: Sage.

Pink, S., Ruckenstein, M., Willim, R. and Duque, M. (2018) 'Broken data: conceptualising data in an emerging world', Big Data E' Society, JanuaryJune, 1-13. DOI: 10.1177/2053951717753228

Postill, J. and Pink, S. (2012) 'Social media ethnography: the digital researcher in a messy web', Media International Australia, 145, 123-134.

Rabinow, P. and Stavrianakis, A. (2014) Designs of the Contemporary. Anthropological Tests. Chicago: University of Chicago Press.

Rheingold, H. (1994) The Virtual Community: Finding Connection in a Computerised World. London: Secker and Warburg. 
Rogers, R. (2009) The End of the Virtual. Amsterdam: Amsterdam University Press.

Rogers, R. (2019) Doing Digital Methods. Thousand Oaks: Sage.

Rojek, C. (2013) Event Power. How Global Events Manage and Manipulate. London: Sage.

Rosa, H. (2015) Social Acceleration. A New Theory of Modernity. New York: Columbia University Press.

Ruppert, E., Law, J. and Savage, M. (2013) 'Reassembling social science methods: the challenge of digital devices', Theory, Culture E' Society, 30(4), $22-46$.

Spitulnik, D. (1993) 'Anthropology and mass media', Annual Review of Anthropology, 22(1), 293-315.

Sumiala, J. (2013) Media and Ritual. Death, Community and Everyday Life. London: Routledge.

Sumiala, J., Tikka, M., Huhtamäki, J. and Valaskivi, K. (2016) '\#JeSuisCharlie: towards a multi-method study of hybrid media events', Media and Communication, 4(4), 97-108.

Sumiala, J., Valaskivi, K., Tikka, M. and Huhtamäki, J. (2018) Hybrid Media Events. The Charlie Hebdo Attacks and the Global Circulation of Terrorist Violence. Bingley: Emerald.

Sumiala, J. \& Räisä, T. (2020) "Our words are stronger”: Re-enforcing boundaries through ritual work in a terrorist news event', International Journal of Cultural Studies. First published 2 January 2020. https://doi.org/10.1177/1367877919895992

Tsing, A. (2002) 'The Global Situation', in Inda, J. X. and Rosaldo, R. (eds), The Anthropology of Globalization. A Reader. Malden, MA: Blackwell Publishing, 453-485.

Urry, J. (2007) Mobilities. Cambridge: Polity Press.

van Dijck, J. (2013) The Culture of Connectivity. A Critical History of Social Media. Oxford: Oxford University Press.

Valaskivi, K., Rantasila, A., Tanaka, M. and Kunelius, R. (2019) Traces of Fukushima. Global Events, Networked Media and Circulating Emotions. Singapore: Palgrave Pivot.

Wagner-Pacifici, R. (2017) What Is an Event? Chicago: Chicago University Press.

Zelizer, B. (2018) 'Seeing the present, remembering the past: terror's representations as an exercise in collective memory', Television E' New Media, 19(2), 136-145. 